\title{
Analysis Of The Causes And Study Of Frequency Of Donor Deferral For Blood Donation
}

\author{
${ }^{1}$ Dr. SmitaMahapatra, ${ }^{2}$ Dr Debasish Mishra, ${ }^{3}$ Dr Gopal Khrusna Ray, \\ ${ }^{4}$ Dr BinayBhusanSahoo, ${ }^{5}$ Dr RashmitaPanigrahi, ${ }^{6}$ Dr SatyabrataPatjoshi, \\ ${ }^{1}$ M.D., Associate Professor, ${ }^{23456}$ Junior Resident \\ Department of Transfusion MedicineS.C.B. Medical College,Cuttack, Odisha,
}

\begin{abstract}
Since blood transfusion is a life saving procedure, the safety and adequacy is ensured by adopting donor deferral criteria with screening of the transfusion transmitted infections(TTI). Aim of the present study is to identify the reasons of temporary and permanent deferral of blood donors. The study was conducted in the Department of Transfusion Medicine, Sriram Chandra Bhanja(SCB) Medical college and Hospital, Cuttack,Odisha,India for a period of one year. Out of 24,710 donors,women were deferred more in number $(1.48 \%)$ in comparison to $1.32 \%$ of male and permanent deferral was less in number $(0.67 \%)$ in comparison to temporary deferral(2.13\%). Hepatitis B infection (84) and anemia (244) constituting the maximum numberaccounted for $50.60 \%$ permanent and $46.29 \%$ temporary deferral respectively. Analysis of the deferral patterns can be helpful to be more focus in donor screening especially those having high frequency of deferral. By follow up of the temporary deferred donors, we can recruit these donors in future which will increase the supply of safe and adequate blood and its components.
\end{abstract}

Key Words: Blood donors; donor deferral; transfusion transmitted infection

\section{Introduction:}

In the present medical and surgical practices, blood transfusion can be life saving, whose requirement is met through the collection of safe blood from healthy donors. According to the survey of national AIDS control organization(NACO), the annual blood collection is quite less, that is 9million in comparison to the annual requirement of 12 million units. ${ }^{1}$ World statistics by World Health Organization (WHO) depicts annual collection of 112.5 million units worldwide constituting, more than half of these are collected in high-income countries home to $19 \%$ of the World's population. ${ }^{2}$ The deficit in the blood collection can be reduced by encouraging blood donation by healthy donors, which will neither harm the donors nor the recipients. This is achieved by proper screening of the donors with stringent deferral criteria either temporary or permanent and screening of collected blood for possible transmission of transfusion transmitted infections. ${ }^{3}$ The present study was conducted to know the demographic profile of blood donors along with the causes and frequency of both temporary and permanent deferrals.

\section{Materials And Methods:}

The present study was conducted in the Department of Transfusion Medicine, Sriram Chandra Bhanja Medical college \& Hospital, Cuttack in the state of Odisha, India for a period of one year from January 2015 to December 2015. All the datas including age, sex, weight, hemoglobin, blood pressure and temperature were recorded. The blood donors were accepted or deferred on the basis of the criteria provided by Drugs \& Cosmetics Act and Rules and Technical Manual ofDGHS. ${ }^{4,5}$ Hemoglobin( $\left.\mathrm{Hb} \%\right)$ was estimated by Hemocue and in the out-door camp site by cupper sulfate method. When blood was dropped from a height of one centimeter,the $\mathrm{Hb} \%$ was recorded to be above $12.5 \mathrm{gm} \%$ if the drop was sinking and less than $12.5 \mathrm{gm} \%$ if the drop floated. Blood samples were screened for Hepatitis B surface antigen(HBsAg) by third generation ErbaLisakit, Hepatitis C Virus antibody by third generation ErbaLisa kit, HIV 1 \& 2 antibody by third generation ErbaLisa kit, malaria rapid kit by MyTest\& syphilis by rapid reagin test by Tulip.

\section{Results:}

Out of 24,710 people who had attended blood-donation siteboth in blood bank and outdoor camp sites, 23,324 were men (94.4\%) and 1386 were women (5.6\%) [Table 1]; 693 donors (2.80\%) were deferred, of which $527(76.04 \%)$ were temporary and $166(23.96 \%)$ were permanent.[Table 2]

Overally, women $(367 ; 1.48 \%)$ were deferred more than men $(326 ; 1.32 \%)$.[Table 3] Moredeferral was seen in the age group less than 30 years $(47.47 \%$ ) in comparison to 30 to 40 years $(29.87 \%)$ and more than 40years(22.66\%) age group. [Table4] Analysis of the deferrals showed that the temporary deferral was more common than permanent deferral. The most common cause in permanent deferral was Type 1 Diabetes Mellitus, 
followed by Asthma.[Table 5] The most common causes among temporary deferral were anemia $(\mathrm{Hb}<12.5 \%)$, followed by weight $<45 \mathrm{~kg}$.[Table6]

Table 1: Demographic profile of the Donors

\begin{tabular}{|l|l|l|l|}
\hline & Registrations & Deferrals & Deferrals of total registrations (\%) \\
\hline Men & 23324 & 326 & 1.32 \\
\hline Women & 1386 & 367 & 1.48 \\
\hline Total & 24710 & 578 & 2.80 \\
\hline
\end{tabular}

Table 2: Frequency of permanent and temporary deferrals

\begin{tabular}{|l|l|l|l|}
\hline & Deferrals & Total deferrals (\%) & Deferrals of total registrations $(\%)$ \\
\hline Temporary & 527 & 76.04 & 2.13 \\
\hline Permanent & 166 & 23.96 & 0.67 \\
\hline Total deferrals & 693 & 100 & 2.80 \\
\hline
\end{tabular}

Table 3: Frequency of deferrals among male and female donors

\begin{tabular}{|l|l|l|l|}
\hline & Donations & Deferrals & Deferrals among male/female donors (\%) \\
\hline Male & 23324 & 326 & 1.40 \\
\hline Female & 1386 & 367 & 26.48 \\
\hline
\end{tabular}

Table 4: Donor deferral in different age group

\begin{tabular}{|l|l|l|l|l|}
\hline SEX/AGE-- & $<30 \mathrm{YR}$ & $30-39 \mathrm{YR}$ & $>=40 \mathrm{YR}$ & TOTAL \\
\hline MALE & 138 & 105 & 83 & 326 \\
\hline FEMALE & 191 & 102 & 74 & 367 \\
\hline
\end{tabular}

Table 5: Causes of permanent deferrals with their relative proportions

\begin{tabular}{|l|l|l|l|}
\hline Causes & Number & Permanent deferrals (\%) & Total deferrals (\%) \\
\hline & & & \\
\hline HBsAg & 84 & 50.60 & 12.12 \\
\hline HCV & 20 & 12.05 & 2.90 \\
\hline HIV & 6 & 3.61 & 0.90 \\
\hline T1 DM & 13 & 7.83 & 1.81 \\
\hline CARDIAC DISEASE & 2 & 1.20 & 0.30 \\
\hline COPD & 8 & 4.82 & 1.15 \\
\hline ASTHMA & 12 & 7.23 & 1.73 \\
\hline EPILEPSY ON MEDICATION & 3 & 1.81 & 0.43 \\
\hline $\begin{array}{l}\text { THYROID DISORDER ON } \\
\text { MEDICATION }\end{array}$ & 8 & 4.82 & 1.15 \\
\hline $\begin{array}{l}\text { PROFFESSIONAL DONORS/ } \\
\text { HIGH RISK BEHAVIOUR }\end{array}$ & 8 & 4.82 & 1.15 \\
\hline OVER AGE $>$ 65YRS & 2 & 1.20 & 0.30 \\
\hline Total & 166 & 100 & 23.95 \\
\hline
\end{tabular}

Table 5: Causes of temporary deferrals with their relative proportions

\begin{tabular}{|l|l|l|l|}
\hline Causes & Number & Temporary deferrals (\%) & Total deferrals (\%) \\
\hline AGE < 18 years & 35 & 6.64 & 5.05 \\
\hline & & & \\
\hline WEIGHT < 45 kg & 104 & 19.73 & 15.00 \\
\hline ANEMIA, Hb< 12.5\% & 244 & 46.29 & 35.20 \\
\hline URTI & 15 & 2.84 & 2.16 \\
\hline ON ANTIBIOTICS LAST 1 YEAR & 36 & 6.83 & 5.20 \\
\hline MINOR/MAJOR SURGERY & 14 & 2.65 & 2.02 \\
\hline MENSTRUATION/PREGNANCY/ & 27 & 5.12 & 3.90 \\
LACTATING MOTHER/DUB & & & \\
\hline ALCOHOL @ 72HR & 19 & 3.60 & 2.74 \\
\hline H/O TB OR ON ATT & 3 & 0.56 & 0.43 \\
\hline DOG OR CAT BITE ARV IG @ 1YR & 1 & 0.18 & 0.14 \\
\hline TATTOO @ 6MONTH & 2 & 0.37 & 0.29 \\
\hline BLEEDING DISORDER & 3 & 0.56 & 0.43 \\
\hline TYPHOID OR MALARIA @ 1YR & 1 & 0.18 & 0.14 \\
\hline JAUNDICE @ 1YR & 1 & 0.18 & 0.14 \\
\hline HYPERTENTION (>160/100 mm Hg) & 17 & 3.22 & 2.45 \\
\hline POOR VEIN & 5 & 0.94 & 0.72 \\
\hline TOTAL & 527 & 100 & 76.04 \\
\hline
\end{tabular}




\section{Discussion:}

The motto of transfusion service should be to provide $100 \%$ safe and adequate blood without exchange. This goal can be achieved by proper donor selection with retention through motivation. Our study was focused on the analysis of the causes of deferral of blood donors to provide adequate blood and blood components guarding the safety of both donors and the recipients. Out of 24,710 persons coming for blood donation, $94.4 \%$ were males \& only $5.6 \%$ were females. But $26.48 \%$ female donors were deferred in comparison to $1.40 \%$ male donors for which anemia was the major contributing factor.

Donor deferral of only $2.80 \%$ was found in the present study which was lower than all previous national study showing deferral of $9 \%$ and international studies where the frequency of donor deferral ranged from $5.6 \%$ to $14.6 \%$. $^{7-10}$

Temporary deferral $(76.04 \%)$ and permanent deferral being $23.96 \%$ were found in the present study. The most common cause among temporary deferral was anemia constituting $46.29 \%$ which is comparable to the study by Halperinet $\mathrm{al}^{11}$ showing $46 \%$ of temporary deferral due to anemia. Anemia can be treated if the donors are kept on iron therapy with follow up. The majority of the deferred donors also belong to the age group of less than 30years. The other causes of temporary deferral were low body weight $(15.01 \%$ of total), on antibiotics within 72 hours $(5.19 \%)$, age below 18 years $(5.05 \%)$ and few conditions like respiratory infections, jaundice, typhoid which are easily curable. A proper track for the follow up of temporarily deferred donors regarding their management should be made in the blood bank so that these donors could be recruited back to the donors pool. The permanent deferral in our study was high (23.96\% of total deferral) due to the inclusion of TTI in the deferral pool. Hepatits B infection was the commonest cause for the permanent deferral constituting $12.12 \% .{ }^{11}$ The finding of HBV infection should be a matter of concern. People should be educated regarding its route of transmission along with vaccination which can reduce the seroprevelence of HBV infection. Adequate and confidential counselling of the donors and distribution of Information, Education, Communication(IEC) pamphlets among the donors will increase self-deferral which in turn will enhance the quality of blood products and reduce wastage of blood and blood components.

\section{Conclusion:}

Donor deferral should be done very stringently to analyze the causes of both temporary and permanent deferral. If temporary deferred donors particularly the young adult donors are followed-up and managed properly, they can be reverted back to the donor pool and increase the supply of safe blood. Permanent deferral like Hepatitis B infection can be reduced by vaccination. Thus determining the cause of donor deferral can guide the donor recruitment effort andprevent loss of precious blood and blood components to provide adequate number of safe blood.

\section{References:}

[1]. Aggarwal S, Sharma V. Attitudes and problems related to voluntary blood donation in India: A short communication.Annals of Tropical Medicine and Public Health 2012;5:50-52.

[2]. www.who.int/mediacentre/factsheets/fs279/en/ Blood safety and availability Update July 2016

[3]. Newman B. Blood donor suitability and allogenic whole blood donation. Transfus Med Rev 2001;15:234-44.

[4]. Zou S, Musavi F, Notari EP, Rios JA, Trouen-Trend J, Fang CT. Donor deferral and resulting donor loss at the American Red Cross Blood Services, 2001 through 2006. Transfusion 2008;48:2531-9.

[5]. Custer B, Johnson ES, Sullivan SD, Hazlet TK, Ramsey SD, Hirschler NV, et al. Quantifying losses to the donated blood supply due to donor deferral and miscollection. Transfusion 2004;44:1417-26.

[6]. Bahadur S, Jain S, Goel RK, Pahuja S, Jain M. Analysis of blood deferral characteristics in Delhi, India. Southeast Asian J Trop Med Public Health 2009;40:1087-91.

[7]. Rabeya Y, Rapiaah M, Rosline H, Ahmed SA, Zaidah WA, Roshan TM. Blood pre-donation deferrals-a teaching hospital experience. Southeast Asian J Trop Med Public Health 2008;39:571-4.

[8]. Arslan O. Whole blood donor deferral rate and characteristics of the Turkish population. Transfus Med 2007;17:379-83.

[9]. Lawson-Ayayi S, Salmi LR. Epidemiology of blood collection in France. Eur J Epidemiol 1999;15:285-92.

[10]. 10)Lim JC, Tien SL, Ong YW. Main causes of pre-donation deferral of prospective blood donors in the Singapore Blood Transfusion Service. Ann Acad Med Singapore 1993;22:326-31.

[11]. Halperin D, Baetens J, Newman B. The effect of short-term,temporary deferral on future blood donation. Transfusion 1998;38:1813 .

[12]. Chauhan Dhaval N, Desai Killol N, Trivedi HarikrishnaJ,Agnihotri Ashok S. Evaluation of blood donor deferral causes: a tertiary care center based study .International journal of medical science and public health 2015;4:389-92. 